\title{
Uma proposta de modelo para as organizações em busca de inovação sustentável
}

\author{
A proposed theoretical model to organizations looking for sustainable \\ innovation
}

\author{
Maira Petrini ${ }^{1}$ \\ Fernando Valentim Pardo Eisele ${ }^{2}$
}

\begin{abstract}
Resumo
A necessidade de atender reivindicações da sociedade relativas a problemas sociais e ambientais tem induzido organizações a buscar estratégias de competitividade socialmente responsáveis e com o mínimo de impacto ambiental. Nesse contexto, a inovação emerge como uma alternativa para o desenvolvimento sustentável. Baseado em uma revisão de literatura que aborda os conceitos de inovação e sustentabilidade, este ensaio procura discutir os conceitos de organização inovadora e organização sustentável, aproximando-os na busca da inovação e de práticas sustentáveis dentro das organizações. Ao final é proposto um modelo de inovação sustentável, na forma de um quadro referencial, que identifica quatro tipos de organização inovadora sustentável: Inercial, Ampliado, Focado e Propagado. Adicionalmente, buscou-se identificar relações entre os quatro tipos, propondo que os mesmos não necessariamente acontecem em uma sequência, como estágios evolutivos, podendo, inclusive, que uma organização seja classificada em dois tipos ao mesmo tempo.
\end{abstract}

Palavras-chave: Inovação. Sustentabilidade. Inovação sustentável. Responsabilidade social corporativa.

\begin{abstract}
To meet society's demands relating to social and environmental problems has led organizations to looking for strategies wich minimize these issues. In this context, innovation emerges as an alternative to sustainable development. Based on a literature review that addresses the concepts of innovation and sustainability, this paper discusses both concepts: the innovative organizational and the sustainable organization, bringing them closer to looking for initiatives of innovation and sustainable within organizations. The conceptual framework proposed for sustainable innovation identifies types and characteristics of each type. The conceptual framework consists of four types of sustainable innovative organization identified from the literature review: inertial, enlarged, focused and pervasive. The relations between them do not happen, necessarily, in a sequence, as evolutionary stages, and also an organization may be classified into two types simultaneously.
\end{abstract}

Keywords: Innovation, sustainability, sustainable innovation, corporate social responsibility.

\section{Introdução}

Diversos autores têm estudado a interdependência entre inovação e sustentabilidade, reconhecendo que a sustentabilidade é um dos principais elementos propulsores da inovação (Nidumolu, Prahalad \& Rangaswami, 2009). Rozenfeld e Forcellini (2009), por exemplo, salientam que a inovação deve ser pautada nos desafios impostos pelo desenvolvimento sustentável, associando ganhos econômicos, atitudes e ações que considerem a preservação ambiental e a responsabilidade social. A compreensão e avaliação das consequências socioambientais devem fazer parte dos processos de inovação (Barbieri, 2004). A abertura do

Pós-doutorado na HEC Montreal - Canadá (2017). Professora adjunta do Programa de Pós-Graduação em Administração da PUC RS. Afiliação: PUCRS. Email: maira.petrini@pucrs.br

2 Mestrado em Administração Estratégica pela PUCRS. Possui graduação em Administração de Empresas pela Pontifícia Universidade Católica do Rio Grande do Sul (1998). Atua como Sócio-Gerente da CoDesign Inteligência em Negócios. Email: eiselers@hotmail.com 
caminho para a diminuição de custos e riscos ou, até mesmo, a promoção da elevação de seus rendimentos e sua participação no mercado, acontece por meio da inovação, de modo que a sustentabilidade passa a ser tratada por algumas organizações como uma oportunidade de negócio (Hart \& Milstein, 2003; Shrivastava, 1995).

Parece clara a relação e a importância dessas duas grandes temáticas aproximando a "organização inovadora" da "organização sustentável". Nessa aproximação reside a definição de organização inovadora sustentável que "não é a que introduz novidades de qualquer tipo, mas novidades que atendam as múltiplas dimensões da sustentabilidade em bases sistemáticas e colham resultados positivos para ela, para a sociedade e o meio ambiente" (Barbieri \& Simantob, 2007, p.105). Entretanto, apesar de termos uma definição clara para conceituar organizações inovadoras sustentáveis, parece que sabemos menos do que gostaríamos sobre o que caracteriza essas organizações.

Froehlich e Bitencourt (2015), adotando a premissa de que a inovação necessita ser tratada como uma capacidade organizacional, analisaram o desenvolvimento da capacidade de inovação como meio de alavancar a sustentabilidade empresarial. Para tanto, necessitaram recorrer à abordagem da inovação, pois a abordagem da inovação sustentável não apresenta modelos que mostram como desenvolvê-la, reforçando a lacuna existente na literatura em relação a uma maior compreensão da organização inovadora sustentável. Dessa forma, este estudo propõe a seguinte questão: Como tornar-se uma organização inovadora sustentável? Na busca dessa compreensão mais profunda, reside o desafio que este ensaio buscou atingir com a proposição de um quadro referencial que identifica uma tipologia para a classificação da organização inovadora sustentável. Para atender tal objetivo, promovemos a conversa entre quatro modelos identificados na literatura. Em três deles, o olhar recai sobre sustentabilidade: Hart e Milstein (2003) focam em criação de valor com estratégias de sustentabilidade, Delgado (2007) tem seu olhar para posturas empresariais com relação ao desenvolvimento sustentável, e Baumgartner e Ebner (2010) focam nos tipos de estratégias de sustentabilidade. O quarto modelo, proposto por Nidumolu et al.(2009), aproxima a temática de inovações com foco em sustentabilidade. A análise comparativa dos quatro modelos levou-nos ao quadro referencial proposto. Como contribuição deste artigo, busca-se a identificação de tipos de organização inovadora sustentável, detalhando suas características, bem como possíveis trajetórias entre os tipos identificados.

Independentemente da motivação para a sustentabilidade empresarial, seja um mandato moral, seja uma exigência legal, muitas organizações percebem a sustentabilidade como uma oportunidade de negócios que oferece alternativas para redução de custos e riscos e/ou aumento na participação no mercado através da inovação (Hart\& Milstein, 2003). Um dos desafios das organizações para explorar essa oportunidade passa por alavancar e desenvolver características organizacionais que contribuam, simultaneamente, para o desenvolvimento sustentável e para oportunidades de inovação. As organizações podem contribuir com os desafios globais associados à sustentabilidade, buscando estratégias e práticas que considerem questões sociais e ambientais impulsionadas por inovações em produtos ou serviços, nos processos ou na estrutura organizacional.

\section{Fundamentação Teórica}

A fundamentação teórica é apresentada em três seções que contemplam os pilares deste artigo: sustentabilidade, inovação e organizações inovadoras sustentáveis

\subsection{Sustentabilidade}

O estudo sobre a necessidade da sustentabilidade não é recente e surgiu como resultado do alto processo de industrialização ocorrido nos três últimos séculos, o que tem gerado uma grande incerteza sobre a subsistência futura do mundo (Oliveira, Martins \& Lima, 2010). Foi a partir do Relatório Brundtland (CMMAD, 1987) que a expressão "desenvolvimento sustentável" passou a ter prestígio em larga escala, e deu-se a conhecer mundialmente por meio da Organização das Nações Unidas (ONU), impulsionando uma mobilização mundial para o desenvolvimento sustentável com o objetivo de "[...] atender às necessidades 
das gerações presentes sem que se comprometa a capacidade das gerações futuras satisfazerem suas próprias necessidades" (CMMAD, 1987, p. 9).

Nesse contexto, o conceito estimula a necessidade de se tomarem medidas para proteger o equilíbrio entre a economia e o entorno ecológico (Silva\& Mendes, 2005). Para integrar a lógica do desenvolvimento, harmonizando as questões ambientais e sociais, surge o conceito do triple bottom line (TBL), tendo recebido esse nome devido à integração das dimensões sociais, econômicas e ambientais, dinâmica que sugere que o sucesso organizacional é medido não apenas pelo lucro gerado pelo negócio, mas também pela integração do desempenho nas dimensões mencionadas (Elkington, 2004).

Elkington (2004) conclui que há três aspectos principais de criação de valor na condução sustentável, são eles: a prosperidade econômica, a qualidade ambiental e a justiça social. Para alcançar a sustentabilidade, é preciso manter uma divisão equitativa das três dimensões - econômica, ambiental e social. Carter e Rogers (2008) reforçam essa proposição referente à integralidade dessas dimensões, sendo a sustentabilidade a área de sobreposição entre elas. De acordo com Barbieri, Vasconcelos, Andreassi e Vasconcelos (2010), o modelo enfatiza a necessidade de empreender esse tipo de gestão equitativa para se obter resultados econômicos, sociais e ambientais positivos. Os autores expandem o conceito do negócio convencional para um enfoque da sustentabilidade que expressa uma nova linguagem na ampliação dos valores sustentáveis nas práticas organizacionais (Skouloudis, Evangelinos \& Kourmousis, 2009).

\subsubsection{Desenvolvimento sustentável no contexto corporativo}

Orchis, Yung e Morales (2002) argumentam que as organizações estão mais conscientes da consequência de seus atos, o que as leva a adotar as práticas de desenvolvimento sustentável como imperativas a sua sobrevivência ou sustentabilidade em longo prazo. Porter e Kramer (2006) identificam quatro motivações que incentivam as organizações a adotar o desenvolvimento sustentável: apelo (dever) moral, sustentabilidade, exigências legais e reputação. $\mathrm{O}$ apelo (dever) moral está relacionado ao fazer a coisa certa, ou seja, a organização precisa agir como um cidadão que age conforme valores considerados corretos pela sociedade. A sustentabilidade se refere ao atendimento das necessidades sociais e ambientais de forma que não comprometa os recursos existentes para as gerações futuras. Atender exigências legais significa uma aceitação das operações da organização pelos públicos envolvidos, por exemplo: governo, comunidades, clientes, entre outros. Por fim, a reputação ocorre quando a organização faz uso da responsabilidade social para a promoção da imagem, objetivando fortalecer a marca e valorizar suas ações.

Com essas motivações como pano de fundo, as organizações podem adotar diferentes tipos de estratégias de sustentabilidade aplicadas aos negócios. Baumgartner e Ebner (2010) apresentam uma classificação de acordo com os objetivos das organizações:

Introvertidas: visam mitigação de riscos. Focam no atendimento aos aspectos legais

e padrões regulatórios externos com relação às questões ambientais e sociais.

Extrovertidas: visam legitimação. Focam na aceitação do público externo e no atendimento a licenças para operação das atividades

Conservativas: visam ecoeficiência. Focam na produção limpa, em prover produtos e serviços com baixo custo e baixo consumo de materiais e energia, e evitar a geração de resíduos e emissão de gases.

Visionários: visam à extensão das questões da sustentabilidade por todas as atividades das organizações. Focam na diferenciação através da inovação e em vantagens competitivas através de condições únicas oferecidas aos stakeholders e clientes.

Conforme Delgado (2007), diversos esquemas de classificação e análise de posturas empresariais com relação ao desenvolvimento sustentável têm sido propostos. A partir do levantamento de diversas propostas de posturas empresariais, Delgado (2007) analisou seus pontos comuns e sugeriu uma forma de classificação das posturas empresariais quanto à aplicação dos princípios do desenvolvimento sustentável. A proposta considera quatro possíveis categorias: reativa, funcional, integrada, proativa. A seguir, apresentase uma síntese do modelo de posturas empresariais de Delgado (2007), a partir das características que compõem cada uma de suas dimensões. 
Reativa: visa controlar o desperdício e prevenir a poluição. Foca em reduzir custos e riscos. Aumentar a eficiência ambiental dos produtos e processos atuais. Atender aos requisitos legais ambientais e sociais.

Funcional: busca gerenciar ciclo de vida. Foca na melhoria da reputação e legitimidade, em desenvolver junto aos seus stakeholders matérias-primas sustentáveis e reduzir os desperdícios, assim como integrar a dimensão ambiental e social às operações.

Integral: foca em inovação sustentável. Foca em criar produtos e serviços sustentáveis, e desenvolver competências para a busca de tecnologias limpas.

Proativa: questiona os negócios. Foca em desenvolver novos modelos de negócio - novos clientes, novos mercados - e buscar a sustentabilidade da sociedade.

Para melhorar a sua competitividade, as organizações podem desenvolver um modelo integrativo e sistêmico de gestão e de práticas que relacionem as áreas econômicas, sociais e ambientais aos seus processos e stakeholders num contexto sustentável. Hart e Milstein (2003, p. 68) afirmam que "os desafios globais associados à sustentabilidade, vistos a partir da ótica dos negócios, podem ajudar a identificar estratégias e práticas que contribuam para um mundo mais sustentável e, simultaneamente, direcionar o valor ao acionista".

Partindo dessa premissa, Hart e Milstein (2003) desenvolveram um modelo que combina a criação de valor para acionistas com estratégias e práticas capazes de promover a sustentabilidade. O modelo foi construído sobre os componentes básicos de criação de valor ao acionista, separadas em dois eixos. 0 eixo vertical trata da necessidade das organizações gerirem os negócios atuais enquanto, simultaneamente, criam as tecnologias e mercados do futuro. O eixo horizontal representa a necessidade de uma organização crescer e proteger as habilidades e recursos organizacionais internos, ao mesmo tempo em que trazem novas perspectivas e conhecimento do mundo externo. A justaposição dessas duas dimensões produz uma matriz com quatro dimensões distintas de desempenho, crucial para a geração de valor para o acionista.

A primeira dimensão, combate à poluição, localizada no quadrante inferior esquerdo, destaca os aspectos do desempenho corrente que são essencialmente internos: redução de custo e risco. São importantes motivadores para a criação de riqueza, que se dá através da redução de perdas e na maior eficiência operacional, proporcionando maiores retornos à organização e aos acionistas.

Gerenciamento de produtos, no quadrante inferior direito, traz a abordagem da preocupação com o desempenho presente e influências externas (stakeholders). O interesse desses stakeholders requer atenção das atividades organizacionais, pois, ao serem considerados, podem levar a organização a uma posição diferenciada, gerando melhorias em sua reputação e legitimidade.

A próxima dimensão, tecnologias limpas, está apresentada no quadrante superior esquerdo, que justifica a preocupação com a criação de produtos e serviços para o futuro, através do desenvolvimento e aquisição de novas habilidades, competências e tecnologias que possibilitarão o crescimento da organização, focando em inovações sustentáveis.

No quadrante superior direito, visão de sustentabilidade, que traz a abordagem das dimensões externas alinhadas ao desempenho futuro da organização. Depende da capacidade da organização em articular uma clara visão de seu caminho e sua trajetória de crescimento.

A inovação atua conjuntamente com a sustentabilidade através do desenvolvimento de processos e/ou produtos inovadores, muitas vezes com investimentos em tecnologias, podendo a economia ser alavancada em paralelo com a preservação ambiental e a equidade social. Segundo Nidumolu et al.(2009), a sustentabilidade pode ser um importante elemento para impulsionar a inovação, devido a necessidade de compreender os desafios do desenvolvimento sustentável.

\subsection{Inovação}

A atividade inovadora envolve um alto grau de incerteza, dependendo não apenas de atividades de pesquisa \& desenvolvimento (P\&D), como também da experiência adquirida e acumulada pelas pessoas e organizações. Kemp, Smith e Becher (2000) consideram a inovação a partir de uma concepção sistêmica de interações complexas entre a organização e o ambiente. Essas relações com o entorno se dão em duas 
instâncias: nas relações entre organizações (dentro da cadeia produtiva) e nas relações entre organizações e todo o ambiente econômico-social e institucional. Na visão de Daroit e Nascimento (2000), a inovação está comumente associada ao enfoque econômico, sendo tratada apenas como forma de obtenção de lucros extras pelas organizações, por meio de vantagens competitivas decorrentes da produção de novos produtos ou processos que agregam valor para o cliente.

Complementarmente, esses autores enfatizam que também é preciso uma maior compreensão por parte das organizações sobre o papel da inovação com relação aos seus efeitos sobre a sociedade e o meio ambiente. Enfim, a inovação pode apresentar-se no produto ou serviço, no processo ou mesmo na estrutura organizacional, e é decorrente de múltiplas interações dentro da própria organização, entre organizações ou, ainda, entre a organização e a sociedade (Dosi, 1988). Nesse contexto, a inovação pode contemplar impactos sociais e ambientais, dando origem à inovação sustentável.

\subsubsection{Inovação sustentável no contexto corporativo}

O desenvolvimento não passa somente pelo crescimento da economia. Ele está relacionado também com a igualdade, a educação, a saúde, o meio ambiente, a cultura e o bem-estar social. Políticas complementares são necessárias, incluindo as mudanças ambientais, que são tratadas com uma dimensão global (Johnson \& Lundvall, 2000). Hall e Vredenburg (2003) entendem que as inovações devem agrupar as necessidades socioambientais, assim como considerar as gerações futuras, com o intuito de alinhar-se ao desenvolvimento sustentável. Nesse contexto, de acordo com Larson (2000), a inovação sustentável é uma força emergente e fundamental para as mudanças nos negócios e na sociedade. Trata-se de uma oportunidade potencial para promover a transformação tecnológica, de produtos e de mercados, levando-se em conta as três dimensões da sustentabilidade (ambiental, social e econômica).

Para Keeble, Topiol e Berkeley (2004, p.3), a inovação orientada pela sustentabilidade pode ser entendida como "a criação de novos mercados, produtos e serviços ou processos orientados por questões sociais, ambientais ou sustentáveis”. Inovação sustentável é, portanto, o processo em que as dimensões sustentáveis (ambiental, social e econômica) são integradas nos processos da organização desde a geração de ideias, passando pela P\&D, até a sua comercialização.

Para fins de entendimento do conceito de inovação sustentável, este será definido como a introdução (produção, assimilação ou exploração) de produtos, processos produtivos, métodos de gestão ou negócios, novos ou significativamente melhorados, para a organização, e que traz benefícios econômicos, sociais e ambientais em comparação com alternativas pertinentes (Barbieri et al., 2010).

\subsection{Organizações Inovadoras Sustentáveis}

Na busca por uma maior compreensão, por parte das organizações, sobre o papel da inovação, com relação aos seus efeitos sobre a sociedade e o meio ambiente, Barbieri e Simantob (2007) defendem o conceito de organização inovadora sustentável, e propõem a compreensão desse conceito através do esclarecimento individual dos conceitos de "organização inovadora" e "organização sustentável". Os autores afirmam que organizações inovadoras são aquelas que introduzem novidades, independentemente do tipo, em bases sistemáticas e, dessa maneira, recebem os resultados que esperam.

A exemplo disso, Hart e Milstein (2003, p.6) definem o conceito de organização sustentável baseado nos três pilares da sustentabilidade: "uma organização sustentável é aquela que contribui com o desenvolvimento sustentável, gerando, simultaneamente, benefícios econômicos, sociais e ambientais". Os dois conceitos de organização podem entrar em contradição, pois inovar em bases sistemáticas pode se tornar sinônimo de degradação sistemática do meio ambiente e da vida social. Assim, uma organização inovadora sustentável "não é a que introduz novidades de qualquer tipo, mas novidades que atendam as múltiplas dimensões da sustentabilidade em bases sistemáticas e colham resultados positivos para ela, para a sociedade e o meio ambiente" (Barbieri \& Simantob, 2007, p.105).

A partir do conceito de inovação, baseado nos três pilares da sustentabilidade, Nidumolu et al. (2009) apresentam o processo da busca da sustentabilidade com base em cinco estágios, cada um com seus desafios 
inerentes. Cada estágio representa uma etapa a ser percorrida pela organização em direção à maturidade para gerir seus produtos/serviços e processos de maneira sustentável para o planeta. Segundo os autores, cinco são os estágios para que as organizações possam transformar seus negócios em sustentáveis e inovadores. São eles:

Respeito às normas como oportunidade - neste estágio, as organizações devem se antecipar e cumprir normas e regulamentações emergentes, pois assim o pioneirismo acarretará em vantagens, da promoção da imagem à inovação;

Tornar a cadeia de valor sustentável - nesse estágio, as organizações trabalham conjuntamente com fornecedores e varejistas para desenvolver matérias-primas e componentes sustentáveis, reduzindo o desperdício. As organizações desenvolvem operações sustentáveis através da análise de cada elo da cadeia de valor;

Criar produtos e serviços sustentáveis - neste, os executivos começam a despertar para o fato de que um número considerável de consumidores prefere produtos e serviços sustentáveis, e que podem alcançar vantagem competitiva ao ser o primeiro a redesenhar os produtos existentes ou mesmo desenvolver novos produtos;

Criar novos modelos de negócio - neste estágio, o desenvolvimento de novos modelos de negócio exigirá alternativas explorando as atuais maneiras de se fazer negócios e compreendendo como as organizações podem atender às necessidades dos clientes de forma diferente;

Criar plataforma de "próximas práticas" - neste, a criação de novas práticas de negócio altera paradigmas existentes. Para desenvolver inovações que levam a novos modelos de negócio, os executivos devem questionar as suposições implícitas por trás das práticas atuais.

Assim, Nidumolu et al. (2009) atrelam essas diferentes fases, pelas quais as organizações passam, ao desenvolvimento de novas competências para inovação e sustentabilidade. A proposição de Nidumolu et al. (2009) aborda o processo de evolução de uma organização até ela se tornar sustentável de forma pragmática. Esse direcionamento é importante, pois serve como um mapa do caminho à frente para abreviar a jornada da sustentabilidade para as organizações.

As organizações inovadoras sustentáveis devem gerar, simultaneamente, resultados econômicos, sociais e ambientais positivos. Os efeitos econômicos são relativamente fáceis de prever, dada a familiaridade das organizações com esta dimensão. Os efeitos sociais e ambientais são mais difíceis de serem avaliados previamente, pois envolvem muito mais variáveis, incertezas e interações. Por isso, o que mais se observa é a continuidade do entendimento convencional, que incorpora o discurso do desenvolvimento sustentável, mas que fica apenas na boa intenção (Barbieri et al, 2010). Este é o desafio que o ensaio busca endereçar ao propor um modelo de organização inovadora sustentável. Buscamos ir além do discurso de incorporar o desenvolvimento sustentável em produtos, processos ou técnicas inovadoras ao apresentar um quadro referencial que descreve as características necessárias para as organizações avançarem nesse sentido.

\section{Modelo de Inovação Sustentável}

Para a proposição do Modelo de Inovação Sustentável foram considerados os modelos de diagnóstico da maturidade das organizações em relação a sua orientação à inovação e à sustentabilidade, como as propostas de Hart e Milstein (2003) e Nidumolu et al. (2009). Adicionalmente, Delgado (2007), que oferece uma classificação das posturas organizacionais em relação ao desenvolvimento sustentável, e os tipos de estratégias de sustentabilidade aplicadas aos negócios propostos por Baumgartner e Ebner (2010). Incialmente, propõe-se uma análise comparativa (Tabela 1) na qual são apresentadas as principais dimensões e características que conceituam os modelos revisitados na literatura. 
Tabela 1

Análise comparativa de modelos revisitados

Características Nidu

Nid.

al. $(2010)$

art e Milste

Baumgartner e

Delgado

Controlar o desperdício e prevenir a poluição, reduzindo custos.

$\begin{array}{llll}\text { NO } & \text { CP } & \text { INT } & \text { REA } \\ & \text { CP } & \text { INT } & \text { REA } \\ \text { NO } & \text { CP } & \text { INT } & \\ \text { NO } & & \text { INT } & \text { REA } \\ \text { NO } & \text { CP } & & \text { REA } \\ & & \text { EXT } & \text { REA } \\ \text { CVS } & \text { GP } & & \text { FUN }\end{array}$

Reduzir custos e riscos.

Aumentar a eficiência ambiental dos produtos e processos atuais (foco em redução de custos).

Atender os requisitos legais ambientais e sociais.

Falta de planejamento social e ambiental.

Focar na sua sobrevivência.

Envolver acionistas, clientes, sindicatos e associações de classe.

Gerenciar ciclo de vida do produto.

GP

EXT

Comunicar ações de sustentabilidade aos stakeholders.

EXT

Buscar junto aos fornecedores, varejistas e stakeholders desenvolver matérias-primas sustentáveis e reduzir os desperdícios.

Crescer e gerar lucro.

Planejamento definido, de curto prazo.

Integrar a dimensão ambiental e social interna às operações.

Criar produtos e serviços sustentáveis do futuro.

Desenvolver competências para a busca de

Tecnologias Limpas.

Integrar a sustentabilidade com suas estratégiaschave de negócio.

CVS GP

FUN

Processo de planejamento foca o médio prazo

(10 anos), sendo integrado ao processo de

planejamento estratégico.

Focar em inovação sustentável.

PSS

TL

VIS

INT

Buscar a perpetuidade da organização.

Questionar os negócios.

$N M N+P P P \quad V S$

VS

PRO

Desenvolver novos modelos de negócio, novos clientes e novos mercados.

Visa à sustentabilidade da sociedade.

$\mathrm{NMN}+\mathrm{PPP}$

VS

VIS

PRO

$N M N+P P P$

VS

VIS

VIS

PRO

Processo de planejamento completamente integrado foca o longo prazo (+ de 10 anos) e fortemente influenciado pelo Desenvolvimento Sustentável.

Visão, valores e cultura são alinhados às questões ambientais e sociais.

FUN

FUN

FUN

INT

INT

(*) NO (Normas como oportunidade), CVS (Cadeia de valor sustentável), PSS (Produtos e serviços sustentáveis), NMN (Novos modelos de Negócios).

${ }^{(* *}$ CP (Combate à poluição), GP (Gerenciamento de produtos), TL (Tecnologias limpas), VS (Visão de sustentabilidade). ${ }^{* * *}$ INT (Introvertida), EXT (Extrovertida), CON (Conservativa), VIS (Visionária).

$\left({ }^{* * \star *}\right)$ REA (Reativa), FUN (Funcional), INT (Integral), PRO (Proativa).

Fonte: Autoria própria (2016). 
A análise comparativa indica similaridades e complementaridades entre os conceitos dos quatro modelos e, à luz desta análise, propõe-se o Modelo de Inovação Sustentável na forma de um quadro referencial (Tabela 2).

\section{Tabela 2}

Quadro referencial - Modelo de inovação sustentável

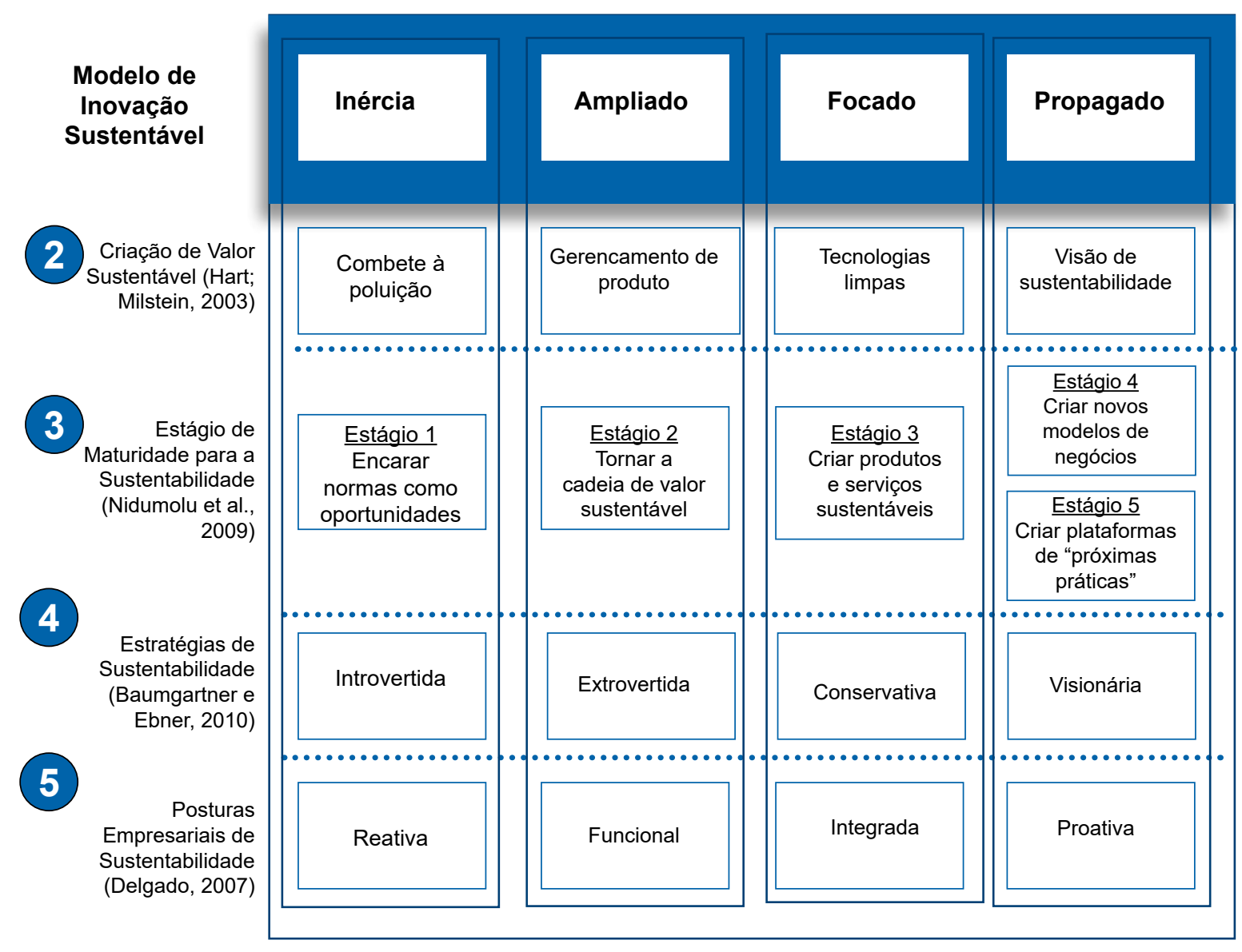

Fonte: Autoria própria (2016).

O quadro referencial é composto de cinco blocos, nos quais é apresentado o alinhamento entre as dimensões de cada modelo revisitado. O primeiro bloco apresenta o Modelo de Inovação Sustentável, o qual é proposto nesta pesquisa como quadro referencial que identifica quatro tipos de organização inovadora sustentável: Inercial, Ampliado, Focado e Propagado. Esse modelo surge a partir do agrupamento dos modelos utilizados como referência (blocos 2, 3, 4 e 5).

No bloco 2, tem-se o modelo de Criação de Valor Sustentável, de Hart e Milstein (2003), o qual fornece uma ferramenta de diagnóstico do valor sustentável da organização. Combina a criação de valor para acionistas com estratégias e práticas, agrupadas em quatro dimensões: (i) combate à poluição, através do aumento de lucros e redução do risco; (ii) gerenciamento do produto, ao se estender além das fronteiras da organização incluindo o ciclo de vida dos produtos - desde a aquisição até o uso do produto e o seu descarte; (iii) tecnologias limpas, acelerando a inovação e o reposicionamento, focada em solucionar problemas ambientais por meio de desenvolvimento ou aquisição de novas competências; e (iv) visão de sustentabilidade, aliando uma estratégia de crescimento futuro a um processo de desenvolvimento de novos produtos e mercados.

O bloco 3 apresenta os Estágios de Maturidade para a Sustentabilidade, propostos por Nidumolu et al. (2009). A proposição desses autores aborda o processo de evolução de uma organização até se tornar sustentável: (i) normas vistas como oportunidade; (ii) tornar a cadeia de valor sustentável; (iii) criar produtos e serviços sustentáveis; (iv) criar novos modelos de negócios; e (v) criar plataforma de "próximas práticas". 
No bloco 4 constam as Estratégias de sustentabilidade propostas por Baumgartner e Ebner (2010): introvertidas, visando a mitigação de riscos; extrovertidas, visando legitimação; conservativas, visando ecoeficiência e visionárias, visando a extensão das questões da sustentabilidade por todas as atividades das organizações.

O bloco 5 contempla a proposta de classificação de Posturas Empresariais de Sustentabilidade, de Delgado (2007), que apresenta 4 níveis, denominadas dimensões, a fim de desenvolver o quadro referencial. São elas: reativa, funcional, integrada e proativa. A classificação proposta por Delgado (2007) traz a ideia de que, no momento em que vários atores sociais têm adotado o desenvolvimento sustentável, as organizações têm sido impulsionadas a tomarem uma posição. Essa escala busca classificar as posturas organizacionais quanto à aplicação dos princípios do desenvolvimento sustentável.

A seguir, apresenta-se uma breve descrição de cada tipo de organização inovadora sustentável proposta no modelo.

Inercial: a organização foca na sua sobrevivência garantindo, no máximo, o atendimento dos requisitos legais e outros padrões regulatórios. Há uma busca pelo controle do desperdício e prevenção da poluição através do aumento da eficiência ambiental dos produtos e processos atuais, mas esses aspectos de desempenho são, essencialmente, internos e de natureza de curto prazo - redução de custos e riscos.

Ampliado: a organização foca no crescimento e na melhoria da reputação e legitimidade. Para tal, atender a requisitos legais e padrões externos torna-se imperativo. Busca integrar as demandas dos diversos stakeholders ao processo produtivo da organização através do gerenciamento do ciclo de vida do produto e através da colaboração extensiva com agentes externos, visando comunicar e ser reconhecida por sua atuação sustentável. Nesse tipo de organização, a inovação é direcionada pelas demandas do mercado.

Focado: a organização foca na sua perpetuidade e, para tal, passa a integrar as dimensões ambientais e sociais à estratégia organizacional, com um olhar interno em produção limpa, em prover produtos e serviços com baixos custos e com baixo consumo de materiais e energia. A organização deve se preocupar com a criação de produtos e serviços sustentáveis com foco em inovação. Tecnologias limpas são fundamentais para os esforços das organizações para reposicionar suas habilidades internas para a busca e desenvolvimento de novos produtos e mercados.

Propagado: a organização, além de focar na sua perpetuidade, assume um papel ativo na transformação da sociedade, visando à sustentabilidade, questionando as formas atuais de fazer negócios e focando na diferenciação através da inovação e de vantagens competitivas. Sua visão, seus valores e sua cultura são alinhados às questões ambientais e sociais, buscando a extensão das questões da sustentabilidade por todas as atividades das organizações.

Entende-se que cada categoria não necessariamente representa uma etapa a ser percorrida pela organização em direção à maturidade. Mesmo assumindo a não linearidade entre os tipos de organização, a passagem pelo tipo Inercial pode ser considerada um estágio inicial. Normalmente, as organizações iniciam sua trajetória rumo à sustentabilidade por força de legislação ou como forma de redução de custos (como a exemplo das campanhas para utilização de canecas recicláveis em detrimento aos copos descartáveis).

Apesar de existir a possibilidade de iniciar já em tipo Focado ou Ampliado, a passagem pelo tipo Inercial possibilita um período de amadurecimento, permitindo a compreensão da própria organização em relação ao seu perfil rumo a ações inovadoras e sustentáveis. A organização poderá escolher entre ter um olhar mais interno para inovação sustentável - tipo Focado, repensando suas operações para se tornarem mais limpas e criando produtos e serviços sustentáveis - ou um olhar mais externo - tipo Ampliado, comunicando as ações de sustentabilidade e desenvolvendo junto aos fornecedores matérias-primas sustentáveis. Entretanto, os dois tipos não são considerados excludentes, ou seja, uma organização pode apresentar características, ao mesmo tempo, que a posicionam tanto como um tipo Focado quanto como um tipo Ampliado. Por fim, para chegar ao estágio Propagado, dado suas características que demonstram a forte integração de sustentabilidade ao negócio, acredita-se que dificilmente uma organização consiga classificar-se nesse tipo sem amadurecer nas questões que envolvem os tipos Ampliado ou Focado. 


\section{Considerações Finais}

A escassez dos recursos é um dos fatores precursores da mobilização da sociedade para a busca da sustentabilidade. As preocupações crescentes em relação às questões sociais e ambientais atingiram o mercado, fazendo com que os consumidores exijam produtos menos agressivos ao meio ambiente, alavancando o consumo sustentável (Briceno \& Stagl, 2006; Mont \& Plepys, 2008). Ao mesmo tempo, é possível perceber uma movimentação das organizações para atender a essa demanda crescente e cada vez mais complexa. Para que as organizações permaneçam nesse mercado competitivo, ambientalmente correto e socialmente responsável, é necessário que haja inovação em seus processos e produtos.

No contexto das organizações, a discussão da inovação e sustentabilidade se faz presente na necessária busca por produtos, processos e serviços sustentáveis. A inovação sustentável é uma força emergente e fundamental para as mudanças dos negócios e das sociedades, buscando proporcionar a transformação tecnológica, de produtos e de mercados, considerando as dimensões ambiental, social e econômica da sustentabilidade (Larson, 2000). Com esse ponto de partida, este artigo buscou contribuir para um maior entendimento desta temática ao propor um modelo de inovação sustentável na forma de um quadro referencial para guiar as organizações no caminho a ser percorrido para se tornarem inovadoras sustentáveis.

Como contribuição teórica, acredita-se que esse modelo avança nos estudos da área, revisitando e resgatando a teoria já existente e construindo uma ponte entre modelos conceituais até então tratados de forma independente. Dessa ponte emerge o quadro referencial que propõe uma tipologia de organizações inovadoras sustentáveis e suas características, além de uma leitura sobre como podem se dar as relações entre os tipos de organização inovadora sustentável identificados. Como contribuição prática, o modelo proposto pode servir como uma ferramenta de autoavaliação para as organizações, pois, ao permitir que as organizações possam se classificar em um (ou mais) tipo(s) e compreender os outros tipos, o quadro referencial pode auxiliá-las em estabelecer ações mais direcionadas, em fortalecer-se no atual perfil ou mesmo mudar seu posicionamento. Acredita-se que esse exercício de autorreflexão sobre o perfil da organização é um importante reforço na consolidação das organizações inovadoras sustentáveis e no estabelecimento de objetivos claros de atuação.

Cabe, ainda, uma consideração em relação ao modelo proposto. Acreditamos que o mesmo possa servir como guideline para as organizações que procuram trilhar o caminho da inovação sustentável. Não temos, com isso, a intenção de propor um frame determinístico, até por não compartilharmos com a ideia que determinismos são possíveis.

Como limitação deste ensaio teórico pode-se apontar as diferenças temporais e epistemológicas entre os modelos utilizados como base teórica. Apesar de ter sido a intenção deste ensaio - promover uma conversa entre modelos já existentes -, nem sempre a comparação entre os modelos aconteceu naturalmente. Uma das razões pode ser o fato de eles terem sido desenvolvidos em tempos distintos, entre 2003 e 2010, período em que diversas discussões ampliaram o conhecimento em relação à sustentabilidade. A outra razão está no fato de partirem de propostas epistemológicas diversas: Nidumolu et al. (2009) tratam de modelo de maturidade para inovações com foco em sustentabilidade; Hart e Milstein (2003) focam em criação de valor com estratégias de sustentabilidade; Delgado (2007) tem seu olhar para posturas empresariais com relação ao desenvolvimento sustentável; e Baumgartner e Ebner (2010) focam nos tipos de estratégias de sustentabilidade.

Como proposta para futuras pesquisas, sugere-se o aprofundamento do modelo proposto na identificação e avaliação de inovações sustentáveis. Neutzling e Silva (2016), ao investigarem a efetivação de sustentabilidade em cadeias de suprimento a partir da visão baseada em recursos (VBR) e da visão relacional (VR), explicam melhor como elementos organizacionais internos à organização podem ser integrados em relacionamentos colaborativos nas cadeias de suprimento. Nesse sentido, um aprofundamento do modelo proposto poderia ser construído investigando-se quais elementos organizacionais internos à organização se manifestam em cada tipo de organização inovadora sustentável proposto no modelo. 


\section{Referências}

Barbieri, J. C. (2004).Gestão ambiental empresarial: Conceitos, modelos e instrumentos. São Paulo: Saraiva.

Barbieri, J. C., \& Simantob, M. (2007). Organizações inovadoras sustentáveis: Uma reflexão sobre o futuro das organizações. São Paulo: Atlas.

Barbieri, J. C., Vasconcelos, I. F. G., Andreassi, T., \& Vasconcelos, F. C. (2010). Inovação e sustentabilidade: Novos modelos e proposições. RAE-Revista de Administração de Empresas, 50 (2), 146-154.

Baumgartner, R. J., \& Ebner, D. (2010). Corporate Sustainability Strategies: Sustainability Profiles and Maturity Levels. Sustainable Development, 18, 76-89.

Briceno, T., \& Stagl, S. (2006). The role of social processes for sustainable consumption. Journal of Cleaner Production, 14(17), 1541-1551.

Carter, C. R., \& Rogers, D. S. (2008). A framework of sustainable supply chain management: Moving toward new theory. International Journal of Physical Distribution \& Logistics Management, 38(5), 360387.

CMMAD. (1987). Nosso futuro comum. Rio de Janeiro: FGV.

Daroit, D., \& Nascimento, L. F. (2000). A busca da qualidade ambiental como incentivo à produção de inovações. Recuperado de http://www.esalq.usp.br/pangea/artigos/pangea_inovacoes.pdf

Delgado, J. (2007). Desenvolvimento Sustentável e a Indústria Química Brasileira: Análise das Posturas Empresariais e proposta de desdobramento das suas estratégias(Tese de Doutorado, Universidade Federal do Rio de Janeiro, Rio de Janeiro). Recuperado de http://docplayer.com.br/78858698-Delgadojorge-juan-soto-desenvolvimento-sustentavel-e-a-industria-quimica-brasileira-analise-das-posturasempresariais-e-proposta-de-desdobramento.html

Dosi, G. (1988). Sources, procedures, and microeconomic effects of innovation. Journal of economic Literature, 26, 1120-1171.

Elkington, J. (2004). Enter the Triple Bottom Line. In A. Henriques \&J. Richardson (Eds.), The Triple Bottom Line: Does it All Add Up? Assessing the Sustainability of Business and CSR. London: Earthscan Publications.

Froehlich, C., \& Bitencourt, C. C. (2015). Proposição de um modelo teórico para capacidade de inovação sustentável. Revista Ciências Administrativas, 21 (2), 555-581.

Hall, J., \& Vredenburg, H. (2003). The challenges of innovating for sustainable development. Mit Sloan Management Review, 45(1), 61-68.

Hart, S. L., \& Milstein, M. (2003). Creating Sustainable Value. Academy of Management Executive, 17(2), 56-69.

Kemp, R; Smith, K; Becher, G. (2000). How should we study the relationship between environmental regulation and innovation?Recuperado de ftp://jrc.es/pub/EURdoc/eur19827en.pdf

Keeble, J., Topiol, S., \& Berkeley, S. (2003) Using Indicators to Measure Sustainability Performance at a Corporate and Project Level. Journal of Business Ethics, 44, 149-158.

Larson, A. L. (2000). Sustainable innovation through an entrepreneurship lens. Business strategy and the environment, 9 (5), 304-317.

Johnson, B; Lundvall, B. A. (2000). Promoting innovation systems as a response to the globalising learning economy. In J. E. Cassiolato, H. M. M. Lastres, \& M. L. Maciel (Eds.), Systems of Innovation and Development Cheltenham: Edward Elgar Publishing. New Horizons In The Economics Of Innovation Serie. 
Mont, O., \& Plepys, A. (2008). Sustainable consumption progress: Should we be proud or alarmed? Journal of Cleaner Production, 16 (4), 531-537.

Neutzling, D. M., \& Silva, M. E. (2016). A sustentabilidade em cadeias de suprimento a partir da visão de recursos e capacidades. Revista Ciências Administrativas, 22(1), 42-71.

Nidumolu, R., Prahalad, C. K., \& Rangaswami, M. R. (2009). Why sustainability is now the key driver of innovation. Harvard Business Review, 87(9), 25-34.

Oliveira, L., Martins, E., \& Lima, G. (2010). Evolução do conceito de sustentabilidade: Um ensaio bibliométrico. Relatórios de Pesquisa em Engenharia de Produção, 10(4).

Orchis, M. A., Yung, M. T., \& Morales, S. C. (2002). Impactos da responsabilidade social nos objetivos e estratégias empresariais. In B. G. Garcia (Colab.), Responsabilidade social das empresas: a contribuição das universidades (vol 1, p.37-70). São Paulo: Editora Peirópolis.

Porter, M., \& Kramer, M. (dec. 2006). Strategy and society: The link between competitive advantage and corporate social responsibility. Harvard Business Review. Recuperado de https://hbr.org/2006/12/ strategy-and-society-the-link-between-competitive-advantage-and-corporate-social-responsibility

Rozenfeld, H., \& Forcellini, F. (2009). Gestão do ciclo de vida de produtos inovadores e sustentáveis. Recuperado de http://www.abepro.org.br/arquivos/websites/27/SD04_Gestao_do_Ciclo.pdf

Shrivastava, P. (1995). Environmental technologies and competitive advantage. Strategic Management Journal, 16(Special Issue), 183-200.

Silva, C. L., \& Mendes, J. T. G. (2005). Reflexões sobre o desenvolvimento sustentável: Agentes e interações sob a ótica multidisciplinar. Petrópolis: Vozes.

Skouloudis, A., Evangelinos, K., \& Kourmousis, F. (2009). Development of an Evaluation Methodology for Triple Bottom Line Reports Using International Standards on Reporting. Environmental Management, 44, 298-311.

Submetido em: 07/05/2018

Aprovado em: 04/02/2019 